.

\title{
LIDERANÇA EMPREENDEDORA E PRÁTICAS DE GESTÃO DE PESSOAS: UM ESTUDO SOBRE A EFICÁCIA NA PROMOÇÃO DO EMPREENDEDORISMO CORPORATIVO
}

DOI: 1014211/regepe33004

\author{
Michele Maria Silva Franco - Faculdade Campo Limpo Paulista ${ }^{1}$ \\ Marcos Hashimoto - Faculdade Campo Limpo Paulista ${ }^{2}$
}

Resumo: Este ensaio teórico explora e consolida estudos realizados sobre as influências das práticas de gestão de pessoas (GP) e a influência de líderes na orientação empreendedora nas organizações. Organizações orientadas ao empreendedorismo fomentam um clima interno que favorece a iniciativa de funcionários para trazer soluções, propostas de mudanças e novas ideias para melhorar o trabalho, a qualidade, o desempenho e a eficácia de processos. Embora exista literatura sobre os fatores que estimulam a orientação empreendedora e os resultados apresentados por estas organizações, a discussão gira em torno de dois grandes grupos de influência, as práticas de GP, institucionalizadas para toda a organização, ou o estímulo do comportamento empreendedor proporcionado pelas lideranças junto às suas equipes. Nessa linha, o presente artigo traz esta discussão intensa em publicações estrangeiras, como pauta para o ambiente acadêmico nacional, consolidando os principais estudos empíricos já realizados. $A$ conclusão do estudo é que as práticas de GP ajudam a criar uma cultura geral em favor da inovação. Porém, é a relação direta do líder com seu subordinado que incentiva a atitude empreendedora de colocar a inovação em prática.

Palavras-chave: Empreendedorismo; liderança empreendedora; orientação empreendedora; práticas de $\mathrm{RH}$.

\section{ENTREPRENEURIAL LEADERSHIP AND HR PRACTICES: A STUDY ABOUT THE EFFICIENCY IN THE PROMOTION OF CORPORATE ENTREPRENEURSHIP}

Abstract: This theoretical essay explores and consolidates studies realized on the influence of managing people (MP) practices and the influence of leaders in entrepreneurial orientation in organizations. Organizations oriented to entrepreneurship foster a climate that favors the initiative of employees to bring solutions, proposals for changes and new ideas to improve their work, the quality, the performance and the effectiveness of processes. Although there is abundant literature about the factors that stimulate the entrepreneurial orientation and the results presented by these organizations, the discussion revolves around two major groups of influence, MP practices, institutionalized to all organization, or the encouragement of entrepreneurial behavior provided by leaders with their teams. In this line, this article brings

\footnotetext{
${ }^{1}$ E.mail: michellysfranco@hotmail.com - Endereço: Rua Guatemala, 167, Jd. América - Campo Limpo Paulista - São Paulo - SP, CEP: 13231-230.

${ }^{2}$ E.mail: prof.hashimoto@uol.com.br
}

FRANCO, M. M. S. Liderança empreendedora e práticas de RH: um estudo sobre a eficácia na promoção do empreendedorismo corporativo. Revista de Empreendedorismo e Gestão de Pequenas Empresas, v. 3, n. 3, p. 104-128, 2014. 
this intense discussion in foreign publications, as an agenda for the national academic environment, consolidating the major empirical studies already performed. The conclusion of the study is that MP practices help to create a general culture in favor for innovation, but is the direct relationship from leader with his subordinate that encourages entrepreneurial attitude to put innovation into practice.

Keywords: Entrepreneurship; entrepreneurial leadership; entrepreneurial orientation; HR practices.

\section{Introdução}

O empreendedorismo é um tema frequentemente abordado nos meios acadêmicos e empresariais nos últimos tempos. A busca do empreendedorismo pelas pessoas como opção de carreira tem gerado um vasto campo de estudos no meio acadêmico e científico. Uma linha de pesquisa que vem se destacando, em particular, é o empreendedorismo corporativo ou empreendedorismo dentro de organizações já existentes.

Segundo Grégoire et al. (2006), o estudo do empreendedorismo no nível da organização tem crescido em dimensão e profundidade, constituindo um importante e consistente eixo de estudo. Schildt, Zahara e Sillanpãã (2006), em pesquisa com base em artigos de 2000 a 2004 em importantes periódicos internacionais, também identificaram o empreendedorismo no nível da organização como um dos temas que mais tem despertado o interesse de pesquisadores da área.

Sabe-se que o mundo empresarial contemporâneo é caracterizado como um ambiente altamente competitivo, globalizado e em constante mudança, o que explica a necessidade das empresas se adaptarem para responderem aos desafios com uma postura empreendedora e aberta para percepcionar novas oportunidades (HAYTON, 2005).

Neste contexto, surge o conceito de Orientação Empreendedora (OE) de Miller (1983), que abrange a aprendizagem organizacional, a criatividade e o empenho individual para promover as mudanças necessárias no ambiente de trabalho (HAYTON, 2005). Contudo, é importante evidenciar que a OE também pode ser considerada como um conjunto de capacidades organizacionais para inovar, renovar e arriscar (ZAHRA; COVIN, 1995).

FRANCO, M. M. S. Liderança empreendedora e práticas de RH: um estudo sobre a eficácia na promoção do empreendedorismo corporativo. Revista de Empreendedorismo e Gestão de Pequenas Empresas, v. 3, n. 3, p. 104-128, 2014. 
Se por um lado a ação empreendedora pode ser desencadeada a partir da iniciativa de alguns indivíduos na empresa, por outro, estas mesmas pessoas precisam sentir o apoio por parte das estruturas formais, sistemas e regras da organização (KURATKO et al., 2005).

Rousseau (1995) afirma que as práticas de gestão de pessoas (GP) desempenham um papel fundamental neste sentido, por determinar quais os comportamentos e recompensas esperadas pelos funcionários. Isto se deve à sua capacidade de criar contratos psicológicos e culturas organizacionais que exercem uma forte influência nos colaboradores, sendo um importante passo para o sucesso organizacional. (HAYTON, 2005).

Por este motivo, cada vez mais as empresas concentram seus esforços no desenvolvimento das melhores práticas de GP, no desenvolvimento de sistemas de $\mathrm{RH}$ mais eficazes na promoção da $\mathrm{OE}$ e, consequentemente, no desempenho das empresas (KAYA, 2006).

Um sistema eficaz de GP inclui atividades, funções e processos direcionados para atrair, desenvolver e manter talentos profissionais na empresa. As práticas de GP incentivam os comportamentos nos funcionários esperados pelos empregadores, por isso é fundamental compreender seu impacto dentro das organizações (LADO; WILSON, 1994).

O estilo de liderança também tem o poder de influenciar a OE da empresa, como resultado de seu impacto na postura dos subordinados. De acordo com (TARABISHY et al., 2005), a liderança empreendedora impacta na postura estratégica da empresa e deve ser levada em consideração para a eficácia das organizações, uma vez que pode ser um fator que influencia na motivação e no comportamento do grupo de trabalho.

Nessa linha, o objetivo deste estudo é investigar os estudos já realizados sobre a influência dos estilos de liderança e das práticas de GP das organizações no que diz respeito à eficácia de ambas as influências na promoção da orientação empreendedora nas organizações. Sugere-se, através desta articulação, o seguinte questionamento: $\mathrm{O}$ que mais influencia a $\mathrm{OE}$ : a liderança empreendedora ou as práticas de gestão de pessoas?

FRANCO, M. M. S. Liderança empreendedora e práticas de RH: um estudo sobre a eficácia na promoção do empreendedorismo corporativo. Revista de Empreendedorismo e Gestão de Pequenas Empresas, v. 3, n. 3, p. 104-128, 2014. 
Este estudo justifica-se pelo crescente interesse pelo tema da OE pela comunidade acadêmica internacional e a carência de estudos empíricos nacionais que consolidem o construto, suas causas e seus efeitos. A consolidação dos principais autores sobre o tema pode ajudar a direcionar futuros trabalhos empíricos no país que possam contribuir para a formação de uma identidade própria de $\mathrm{OE}$ dadas as circunstâncias existentes das práticas de gestão de pessoas (GP) e estilos de liderança de gestores em empresas no Brasil.

Desta forma, este estudo está dividido em três seções. A primeira compreende esta introdução e a principal proposição que orienta o estudo. A segunda trata da revisão de literatura sobre empreendedorismo, OE, práticas de GP, liderança, liderança empreendedora, seguida da discussão. A terceira seção apresenta a conclusão que resume a contribuição que este estudo pode proporcionar junto à academia.

Para atingir o objetivo deste estudo de avaliar a influência da liderança empreendedora e práticas de GP em organizações na eficácia da promoção da orientação empreendedora, foram definidas as seguintes proposições que serão devidamente testadas ao longo da revisão de literatura:

P1. Liderança empreendedora exerce mais influência que práticas de GP na formação da OE.

P2. Práticas de GP exercem mais influência que liderança empreendedora na formação da OE.

P3. Nem liderança empreendedora, nem práticas de GP, exercem influência sobre a formação da OE.

P4. Tanto a liderança empreendedora como as práticas de GP exercem igual influência na formação da OE.

\section{Empreendedorismo}

Empreendedorismo é um tema que vem sendo amplamente abordado juntamente às comunidades acadêmicas e empresariais nos últimos tempos. Segundo Schumpeter (1947), é o papel da inovação no processo empreendedor que resulta na criação de novos métodos de produção, novos produtos e mercados:

FRANCO, M. M. S. Liderança empreendedora e práticas de RH: um estudo sobre a eficácia na promoção do empreendedorismo corporativo. Revista de Empreendedorismo e Gestão 
[...] o empreendedor é a pessoa que destrói a ordem econômica existente graças à introdução no mercado de novos produtos/serviços, pela criação de novas formas de gestão ou pela exploração de novos recursos materiais e tecnologias (SCHUMPETER, 1947, p. 158).

Na concepção de Timmons e Spinelli (2004), o empreendedor é alguém capaz de identificar, agarrar e aproveitar oportunidades, buscando e gerenciando recursos para transformar a oportunidade em negócios de sucesso.

Empreendedorismo, entretanto, não caracteriza apenas a pessoa que está começando um novo negócio sozinho, mas também, grandes empresas já existentes que podem fomentar o empreendedorismo como forma de alavancar as inovações tecnológicas de seus produtos e/ou serviços (DRUCKER, 1987).

Dentro do campo do empreendedorismo, a Orientação Empreendedora (OE) é um dos temas que têm atraído à atenção de diversos pesquisadores (GRÉGOIRE et al., 2006; SCHILDT; ZAHRA, SILLANPÃ̃̃, 2006) e que será detalhado a seguir.

\section{Orientação empreendedora}

A partir da aplicação do conceito de empreendedorismo à organização, surge a orientação empreendedora, que se refere ao processo empreendedor, ao empreendedorismo no nível da organização. Originalmente, o conceito de $\mathrm{OE}$ emergiu da literatura do gerenciamento estratégico. Como decorrência disto, tem sido uma tendência usar conceitos provenientes dessa literatura para observar o empreendedorismo no nível da organização, de forma especial os estudos de Covin e Slevin (1989, 1991); Miller e Friesen (1982) e Miller (1983).

A OE refere-se ao processo no qual o empreendedorismo se desenvolve (LUMPKIN; DESS, 1996), os métodos, práticas e estilos de tomada de decisão gerencial usados para agir de forma empreendedora, emergindo de uma perspectiva de escolha estratégica, na qual oportunidades de novos negócios podem ser empreendidas com sucesso e de forma intencional. Este processo envolve as intenções e ações de atores-chave, funcionando em um processo dinâmico que visa 
à criação de novos negócios. Conforme proposto por Covin e Slevin (1991), a OE pode ser encarada como uma postura empreendedora permeando a visão e as operações de uma organização.

As origens dos fundamentos da Orientação empreendedora (OE) encontram referências nos trabalhos de Longenecker e Schoen (1975), que estabeleceram os três componentes fundamentais desse construto:

1) Inovação - Empreendedorismo está associado à ação inovadora ou criativa e envolve a criação de produtos, serviços, processos, negócios, mercados, alternativas de materiais e mudanças estruturais na organização;

2) Autonomia - O empreendedor deve gozar de autonomia para tomar a decisão pelo uso de recursos, estabelecimento de objetivos, escolha de estratégias de ação e busca de oportunidades relevantes;

3) Propensão a tomar riscos - Toda iniciativa empreendedora envolve algum grau de risco. Quanto maior o fator de inovação, maior é a incerteza, componente fundamental do risco, junto com o fator probabilidade.

Miller (1983) incluiu o componente "pró-atividade", justificando como sendo a "implementação do que for necessário para antecipar e agir sobre uma oportunidade empreendedora, com perseverança, adaptabilidade e tolerância a riscos". Em 1989, Covin and Slevin adicionaram "agressividade competitiva" ao construto de OE como sendo a capacidade da organização de responder a tendências e demandas que existem no ambiente de mercado.

Assim, Orientação Empreendedora pode ser definida como o conjunto de processos-chave, práticas e atividades de tomada de decisão que levam as organizações a iniciar novos empreendimentos (LUMPKIN; DESS, 1996), sendo constituída pelas dimensões de inovação, autonomia, pró-atividade, propensão a assumir riscos e a agressividade competitiva (COVIN; COVIN, 1990).

Neste sentido, como a base que caracteriza a $\mathrm{OE}$ envolve algumas dimensões relacionadas com comportamentos organizacionais que proporcionem a formação desta postura empreendedora e suscitem a atitude proativa dos colaboradores para conceber e implantar suas ideias (HASHIMOTO, 2006; 
LUMPKIN; DESS, 1996), torna-se inevitável envolver nesta discussão, as práticas realizadas pelas empresas direcionadas para o comportamento organizacional.

\section{Práticas de gestão de pessoas}

As práticas de gestão de pessoas são um importante passo para o sucesso organizacional, desenvolvido por meio de sistemas mais eficazes (KAYA, 2006), que incluem atividades, funções e processos focalizados para atrair, desenvolver e manter talentos na empresa (LADO; WILSON, 1994).

Lado e Wilson (1994) entendem que os profissionais de GP podem ajudar a formular a visão e a missão da organização, influenciar a alta administração na síntese de informação e conhecimento sobre os empregados, além de contribuir significativamente para a construção de competências organizacionais na seleção, treinamento e desenvolvimento dos empregados e de suas competências (o que envolve também o desenvolvimento de comportamentos adequados à estratégia).

Algumas práticas são propulsoras de um espírito empreendedor na empresa. Nas últimas décadas, tem-se visto evidências teóricas e empíricas sobre a relação entre as práticas de gestão de pessoas e a orientação empreendedora (MORRIS; JONES, 1993), o que será detalhado a seguir.

\section{Práticas de gestão de pessoas e orientação empreendedora}

Para a implantação de uma cultura voltada ao empreendedorismo, as organizações precisam de recursos empreendedores (BRATNICKI, 2005). Tais recursos se caracterizam pelos aspectos organizacionais que favorecem a instituição da prática empreendedora, como liberdade, autonomia e resiliência, que são, na sua maioria, considerados intangíveis. A contribuição deste tipo de recurso depende da eficácia das práticas e procedimentos organizacionais orientados para este fim e favorecidos institucionalmente pelas áreas de desenvolvimento organizacional (KAYA, 2006).

FRANCO, M. M. S. Liderança empreendedora e práticas de RH: um estudo sobre a eficácia na promoção do empreendedorismo corporativo. Revista de Empreendedorismo e Gestão de Pequenas Empresas, v. 3, n. 3, p. 104-128, 2014. 
Nesta lógica, a quantidade de ações empreendedoras pode ser reflexo das práticas adotadas pela organização em relação à gestão de pessoas (KURATKO; MONTAGNO; HORNSBY, 1990), em que a orientação empreendedora é um indicador da efetividade de tais práticas (HAYTON, 2003). Algumas delas (e.g. formação, desenvolvimento) podem proporcionar uma cultura de inovação, de criatividade e de iniciativa (BROCKBANK, 1999), propulsoras do espírito empreendedor na organização.

Nas ultimas décadas, tem surgido um corpo de evidências teóricas e empíricas sobre a relação entre as práticas de gestão de pessoas (GP) e a orientação empreendedora (OE). Nesse sentido, Morris e Jones (1993) argumentam que de todas as áreas decisivas de gestão que afetam a OE, a GP parece ser uma das mais vitais. Schuler (1986, p. 5) sugere que "para as empresas a questão não é se devem ou não exercer a atividade empreendedora, mas sim o que fazer para encorajar o estabelecimento de empreendedorismo".

Morris e Jones (1993) salientam, ainda, a importância das práticas de GP na criação de valores e dinâmicas, e consideram que, para muitas empresas, a questão não é em que área devem "abraçar" o empreendedorismo, mas o que podem fazer para estimular a inovação, a aceitação do risco e o comportamento proativo das pessoas. Desta forma, a OE da empresa requer que os trabalhadores estejam aptos para pensarem e agirem de novas maneiras, aceitarem responsabilidade individual para a mudança e colaborarem simultaneamente em equipes.

Dessa maneira, as investigações sobre a relação entre as práticas de GP e a OE tornaram-se particularmente relevantes, tal como se pode observar no Quadro 1, que consolida as principais contribuições de estudiosos do tema: (HAYTON, 2003, 2005; KAYA, 2006; MORRIS; JONES, 1993; SCHULER, 1986). 
PRÁTICAS/POLITICAS DE GP

Recrutamento e Seleção Formação $e$

Desenvolvimento Avaliação de Desempenho

Recompensas
IMPACTO NA OE

Promovem características

associadas à $\mathrm{OE}$ (e.g. criatividade, comportamento inovador, aceitação de risco, orientação em longo prazo, tolerância à ambiguidade $\mathrm{e}$ preferência por assumir responsabilidade)

Avaliação de desempenho compensação e recompensa formação e desenvolvimento recrutamento e seleção desenho do trabalho Políticas de GP orientadas para: inovação, aceitação de risco, longo prazo, resultados, individualismo, flexibilidade, participação, focalização externa.

Uso apropriado de recompensas oferta de apoio de gestão para a inovação viabilidade dos recursos para a inovação aceitação individual do risco aprendizagem atividades em equipe Recrutamento e seleção formação e desempenho recompensas segurança $e$ desenvolvimento de carreiras

Práticas tradicionais - e.g. desenho do trabalho com base nas tarefas e responsabilidades ; recompensas; processo de avaliação de desempenho formal -.

Práticas discricionárias - e.g. incentivos de pagamentos, esquemas formais de participação de trabalhadores; orientação para resultados; autonomia e empowerment; participação dos colaboradores -.

Formação intensiva como a formação em competências alargadas políticas formalizadas atividades em equipe, incentivos para alcançar objetivos, comunicação, facilidades de interação

QUADRO 1 - Sistematização dos principais contributos sobre a relação entre as práticas de $\mathrm{RH}$ e da OE

Fonte: Palminha, M. A. S. (2009). O impacto das práticas de Gestão de Recursos Humanos e da Orientação Empreendedora no desempenho das empresas Portuguesas. 84 fls. Dissertação (Mestrado em Economia). Faculdade de Economia. Universidade do Porto.

Em seu trabalho, Schuler (1986) aponta que o nível de empreendedorismo organizacional pode ser influenciado por um número de políticas e práticas de $\mathrm{RH}$, e

FRANCO, M. M. S. Liderança empreendedora e práticas de RH: um estudo sobre a eficácia na promoção do empreendedorismo corporativo. Revista de Empreendedorismo e Gestão de Pequenas Empresas, v. 3, n. 3, p. 104-128, 2014. 
sugere que para cada um dos domínios de GP, recrutamento e seleção, formação e desenvolvimento, avaliação de desempenho e recompensas, existem várias modalidades de práticas de GP que podem fomentar mais ou menos, características empreendedoras nos empregados.

Por exemplo, para promover características associadas a esforços empreendedores deve-se estimular a criatividade, o comportamento inovador, a aceitação de risco, visão de longo prazo, tolerância, a ambiguidade e preferência para assumir responsabilidades. Estes critérios deverão ser valorizados pelas diferentes práticas nos domínios de gestão de pessoas (GP) (SCHULER, 1986; MORRIS; JONES 1993).

Morris e Jones (1993) apontaram também no estudo, que as quatro práticas de GP propostas por Schuler (1986), juntamente com o desenho do trabalho, estão positivamente associadas à OE. Os autores concluíram empiricamente que a adoção destas práticas de GP tem impacto positivo no nível de empreendedorismo demonstrado pela organização, isto é, os gestores pesquisados perceberam qual o nível de empreendedorismo desejável na sua organização e determinaram a adoção de certas práticas de GP que levaram ao aumento do nível de OE na organização.

Em consonância com estes achados, (HORNSBY; KURATKO; MONTAGNO, 1999; TWOMEY; HARRIS, 2000) identificaram práticas de GP que incentivam comportamentos empreendedores nos colaboradores das empresas. Hornsby, Kuratko e Montagno, (1999) apontaram em estudo, fatores de sucesso do ambiente organizacional (uso apropriado das recompensas, suporte organizacional e disponibilidade de recursos para a inovação, estrutura organizacional que conduz a cooperação e aceitação de risco) que pressupõem comportamentos empreendedores.

Já Twomey e Harris (2000), reportaram evidências que demonstram a relação entre um pacote de práticas de GP e a orientação empreendedora (OE), ao explorarem o empreendedorismo integrado ao âmbito da GP, que surge neste contexto como estratégia competitiva. Jones, Morris e Rockmore, (1995) realizaram um estudo para aferir quais práticas promovem e facilitam o empreendedorismo por meio de um estudo empírico que considera especificamente a ótica dos gestores.

FRANCO, M. M. S. Liderança empreendedora e práticas de RH: um estudo sobre a eficácia na promoção do empreendedorismo corporativo. Revista de Empreendedorismo e Gestão de Pequenas Empresas, v. 3, n. 3, p. 104-128, 2014. 
Hayton (2003) investigou de que forma a GP pode promover um desempenho empreendedor, distinguindo práticas tradicionais e discricionárias. Os resultados comprovaram que as últimas, ou seja, escolhidas de acordo com a conveniência e preferência de seus praticantes, encorajavam mais o compromisso do trabalhador, a cooperação, a partilha de conhecimento e a realização de atividades voluntárias fora do quadro de atribuições do funcionário. Em oposição, as práticas tradicionais, focam-se essencialmente na definição do trabalho. Neste mesmo estudo, Hayton (2003) demonstrou que as práticas discricionárias promovem a OE.

Kaya (2006) direcionou seus estudos na busca de relações entre a OE e o desempenho da empresa, quer de forma direta, quer através dos seus efeitos nas práticas de gestão de pessoas.

Como se observa, todos estes estudos demonstram a influência das práticas de $\mathrm{RH}$ no comportamento empreendedor dos colaboradores das empresas. Assim, é importante discutir a influência da liderança na OE.

\section{Liderança}

É importante começar a discussão sobre liderança citando Drucker (1996, p. 141), para quem:

"Um primeiro princípio de liderança é que esta é uma relação entre líder e seguidores. Sem seguidores não há o que liderar. Um segundo princípio é que líderes eficazes não só estão a par, como gerenciam conscientemente a dinâmica desta liderança".

A liderança é, portanto, o processo de exercer influência sobre os indivíduos, concentrando os esforços para a realização dos objetivos (HERSEY; BLANCHARD, 1996). O líder é percebido pelo grupo como sendo capaz de defender objetivos que são legitimados e aceitos pelo grupo (TALES, 1981).

Como o líder é o influenciador dentro da organização, em um ambiente de mudanças precisa ser empreendedor e facilitador dos processos, além de 
modelador do ambiente de trabalho, conciliando as necessidades dos colaboradores com as da empresa (TALES, 1981).

A dinâmica da liderança atual está concentrada naquele que determina 0 que deve ser feito e supervisiona a execução, pensando não só no que deve ser feito, mas influenciando e conduzindo seus liderados. Para este fim, o líder precisa conhecer as pessoas, saber lidar com as emoções e desejos de cada liderado, desenvolvendo neles a vontade de alcançar os resultados propostos (KIRKPATRICK; LOCKE, 1991).

Sendo assim, é necessário que o líder saiba detectar as características de personalidade dos liderados, utilizando essa informação para auxiliar nas decisões e orientações dadas a eles. Isto pode proporcionar uma relação de empatia com a equipe que facilitará a execução das tarefas, propiciando um clima harmônico e tranquilo no ambiente organizacional (COOPER, 1997).

O líder deve ser perspicaz para direcionar as tarefas ao colaborador que tem mais condições de resolvê-la com eficácia. Para isso, ele associa as oportunidades às características pessoais do colaborador. Espera-se que o líder em qualquer nível da organização seja um mentor, treinador, conselheiro, aliado e amigo. Exige-se do líder competências em comunicação oral e escrita, capacidade de escutar, negociar, administrar conflitos, estabelecer estratégias e táticas e influenciar positivamente o comportamento das pessoas com quem trabalha. Deseja-se também que o líder possua qualidades tais como: honestidade, ética, energia, flexibilidade, comprometimento, empatia, sensibilidade, intuição, bom humor, consciência e humildade (KIRKPATRICK; LOCKE, 1991).

Pode parecer muito difícil reunir em uma única pessoa tantas características, mas o conhecimento profundo de si mesmo, das atividades que desenvolve, da equipe que lidera e a observação das circunstâncias gerais da situação, levam o líder intuitivamente às escolhas mais acertadas. Quando o líder observa a situação com domínio de seus sentimentos, vai perceber, com poucas chances de erro, qual a escolha mais acertada (COOPER, 1997).

Os estudos sobre liderança têm focado diferenças de estilos e suas influências nas organizações. Dentre estes estudos, surgiu um novo tipo de liderança que auxilia a tornar a organização capaz de enfrentar novos desafios, a 
"liderança empreendedora" (MCGRATH; MCMILLAN, 2000; TARABISHY et al., 2005), que será abordada na sequência.

\section{Liderança empreendedora}

Estudos empíricos sugerem que a orientação empreendedora (OE) da empresa provém da liderança e da orientação de seus principais executivos (SADLER-SMITH; EL-KOT; LEAT, 2003; TARABISHY et al., 2005). A teoria de gestão estratégica também atesta que os gerentes de alto escalão têm impacto efetivo na formulação estratégica (WIKLUND, 1999).

Nos últimos 30 anos, os estudos sobre liderança têm focado diferenças de estilos e suas influências nas organizações. Alguns pesquisadores argumentam a necessidade do estudo de um novo tipo de liderança que auxilie a tornar a organização capaz de enfrentar novos desafios (MCGRATH; MCMILLAN, 2000; TARABISHY et al., 2005).

Esse novo tipo de liderança tem sido chamado de "liderança empreendedora", sendo explicado pela manifestação de características e comportamentos empreendedores e de liderança (IRELAND; HITT, 1999; MCGRATH; MCMILLAN, 2000).

Este estilo de liderança influencia a OE da empresa como resultado de seu impacto na postura dos subordinados e na postura estratégica da organização (TARABISHY et al., 2005).

De acordo com Timmons e Spinelli (2004) o líder empreendedor se diferencia do comum em diversos aspectos, pois este último apenas deixa impostas suas ideias sem a participação das pessoas. Por outro lado, o líder empreendedor percebe que para transformar a empresa e atingir seus objetivos, precisa estar em contato direto com os colaboradores, participando junto dos trabalhos desenvolvidos e proporcionando oportunidade para que esses trabalhadores também desenvolvam um perfil empreendedor. Havendo uma estrutura organizacional apropriada e o 
envolvimento de um líder empreendedor, é possível inserir mudanças e inovações na empresa a partir de indivíduos empreendedores (TIMMONS; SPINELLI, 2004).

Um líder empreendedor tem uma visão mais crítica e reivindicativa perante as atitudes e ações que deve desempenhar, devendo saber ajudar cada membro da equipe a ajustar o seu comportamento para o alcance das metas e a encontrar a sua satisfação pessoal nesta trajetória. Para isso, precisa basear a sua gestão na confiança, na valorização das pessoas, na sinergia, na cooperação e em um processo de comprometimento e de envolvimento mental constante e negociado (ROBBINS, 2002).

Assim, a liderança empreendedora deve ser levada em consideração para a eficácia das organizações, uma vez que pode ser um fator que influencia na motivação e no comportamento do grupo de trabalho (TARABISHY et al., 2005).

\section{Discussão}

A partir da aplicação do conceito de empreendedorismo à organização, surge a orientação empreendedora, que se refere ao processo empreendedor, ao empreendedorismo no nível da organização.

Sabe-se que a orientação empreendedora pode estar presente em maior ou menor intensidade (LUMPKIN; DESS, 1996) e que ela pode ser trabalhada (COVIN; SLEVIN, 1991), mas para isso, é necessário que haja condições adequadas, que sejam considerados alguns elementos e a forma de trabalhá-los. Segundo Miller (1983), diferentes organizações requerem diferentes tipos de forças para estimular a orientação empreendedora.

A ação empreendedora pode ser desencadeada a partir da iniciativa de alguns indivíduos na empresa. Isto fica evidente ao constatar que as dimensões da orientação empreendedora (inovação, risco, autonomia, pró-atividade e competitividade agressiva), embora caracterizem organizações orientadas ao empreendedorismo, residem em pessoas que precisam sentir o apoio por parte das estruturas formais, sistemas e regras da organização (KURATKO et al., 2005).

Desta forma, o principal ponto de discussão neste artigo diz respeito às duas principais formas de despertar o interesse intrínseco das pessoas a agir de forma 
empreendedora: por meio de práticas institucionalizadas orientadas para este fim e capitaneadas na estrutura da organização, pela gestão de pessoas ou órgãos similares, ou, ainda, por meio da ação direta de líderes de áreas, departamentos ou equipes diretamente sobre seus liderados.

A literatura, como já apresentado anteriormente, suporta de forma equivalente a influência de ambas na orientação empreendedora. Rousseau (1995) afirma que as práticas de gestão de pessoas desempenham um papel fundamental, pois constitui importante mecanismo por meio do qual as empresas estabelecem quais os comportamentos esperados e recompensas fornecidos aos seus trabalhadores. Isto se deve à sua capacidade de criar contratos psicológicos e culturas organizacionais que exercem influência sobre os colaboradores, sendo um importante passo para o sucesso organizacional (HAYTON, 2005).

Tais contratos, quando não estabelecidos pelas equipes, devem ser estimulados formalmente por meio de regras, políticas e códigos de conduta apropriados para cada tipo de empresa e cada negócio, segundo a natureza intrínseca que permeia as atividades realizadas pela equipe.

Embora muitos destes contratos estabeleçam um padrão para garantir um mínimo de ordem e segurança, são cada vez mais necessários na medida em que a organização cresce e se torna mais complexa. Alguns destes contratos prescrevem uma relação na qual os funcionários podem exercer certas liberdades e autonomias para compartilharem, desenvolverem e implantarem suas ideias próprias de melhoria do trabalho.

Assim, as práticas de gestão de pessoas (GP) exercem influência sobre a orientação empreendedora (OE) e incentivam comportamentos empreendedores nos colaboradores das empresas. Isto acontece, em linhas gerais, por dois caminhos: introdução de políticas que propõem recompensas por ações e práticas espontâneas que levam a resultados positivos ou pela eliminação de regras que possam limitar e constranger a criatividade e a liberdade para que os funcionários coloquem em prática suas ideias.

Dois dilemas são enfrentados pelas divisões de gestão de pessoas ao estabelecer os critérios para flexibilizar suas regras em favor de uma orientação mais empreendedora dentro da organização. O primeiro é o fato de que nem todos

FRANCO, M. M. S. Liderança empreendedora e práticas de RH: um estudo sobre a eficácia na promoção do empreendedorismo corporativo. Revista de Empreendedorismo e Gestão de Pequenas Empresas, v. 3, n. 3, p. 104-128, 2014. 
os funcionários possuem perfil empreendedor e por este motivo, a falta de uma regra que pode favorecer um funcionário com perfil empreendedor pode levar a decisões equivocadas por parte de um funcionário que não souber ou não quiser usufruir de tal liberdade.

As regras e práticas de GP visam estabelecer ordem e padrões para garantir, dentro do escopo de gestão de pessoas, que todos sejam tratados de forma igualitária e justa, bem como seja possível reconhecer e recompensar os talentos que melhor se destacam em suas atividades. No entanto, como as pessoas são diferentes entre si, nem sempre uma prática pode ser interpretada da mesma forma ou ser avaliada sob os mesmos critérios por todos. Por exemplo, uma prática comum é o registro do horário de entrada e saída dos funcionários. Sob um ponto de vista, este registro favorece o processo de atribuição de remuneração adicional para os funcionários que executam horas extras, facilita o controle dos supervisores sobre absenteísmo e provê um parâmetro adicional de desempenho da organização. Este mesmo registro, porém, se disseminado igualmente a toda organização, pode penalizar pessoas que são obrigadas a abrir mão de projetos de alta importância para a organização porque não podem se dedicar a ele ou não podem vir à empresa fora do horário de trabalho, normalmente quando sua mente está mais propícia a desenvolver trabalhos de natureza intelectual.

Desta forma, descrições de cargo ajudam a esclarecer ao funcionário o que é minimamente esperado na sua função, mas limita o funcionário que deseja fazer mais do que lhe é exigido. Avaliações de desempenho ajudam a definir critérios de recompensas, mas não premiam funcionários que contribuem com outras realizações não previstas. Promoções e aumentos salariais premiam aqueles que trazem resultados cada vez superiores, mas não incentivam a experimentação pelo novo e assim por diante.

Esperar que todos os funcionários tirem igual proveito de práticas que favorecem o comportamento empreendedor pode ser uma falácia e um pressuposto perigoso quando mal interpretados por trabalhadores que não são empreendedores.

O segundo dilema diz respeito à decisão de quais regras manter e quais flexibilizar. Independentemente do perfil empreendedor do trabalhador, os critérios para estabelecer "exceções à regra" para favorecer a adoção de uma iniciativa de

FRANCO, M. M. S. Liderança empreendedora e práticas de RH: um estudo sobre a eficácia na promoção do empreendedorismo corporativo. Revista de Empreendedorismo e Gestão de Pequenas Empresas, v. 3, n. 3, p. 104-128, 2014. 
natureza empreendedora ou inovadora não são fáceis de definir, dado que as iniciativas podem ser dos mais diferentes tipos e nem sempre cobertos pelos mesmos critérios.

Apesar de este dilema estar intrinsecamente ligado ao anterior, o ponto de discussão aqui apresentado é suportado pela característica das práticas organizacionais, a sua institucionalização, ou seja, o fato de ela ser indistintamente aplicada para toda a organização e não de acordo com o perfil empreendedor do funcionário. Por exemplo, se a prática for o estabelecimento de um plano de carreira ao qual qualquer funcionário possa ter acesso e que implica na ascensão por meio de cargos a posições de maior responsabilidade e melhores recompensas ao longo da pirâmide hierárquica, áreas essencialmente orientadas por projetos acabam tendo que se adequar a um modelo organizacional não desenhado para este fim, como áreas de Pesquisa e Desenvolvimento, Novos Negócios ou de Engenharia de Produtos.

Esperar que uma organização naturalmente complexa pelo seu tamanho, pela diversidade de negócios, pela amplitude de cobertura territorial ou pelas suas características operacionais, possa se adequar a práticas que promovam uma orientação empreendedora que são, em geral, particulares e específicas é adotar um cobertor curto que pode atender a alguns, mas certamente deixará outros descobertos.

Não é de se espantar, assim, que as organizações busquem outros caminhos para promover o comportamento empreendedor tão necessário para gerar as inovações que levam à competitividade sustentável. Uma delas é o trabalho específico junto às lideranças e seu impacto dentro das organizações (KAYA, 2006).

Como o líder é o influenciador dentro da organização, em um ambiente de mudanças, ele precisa ser empreendedor para facilitar processos voltados à inovação e mudança, além de ser o modelador do ambiente de trabalho, conciliando as necessidades dos colaboradores com as da empresa (TALES, 1981).

As restrições impostas pelas práticas institucionalizadas que se tornam mais evidentes na medida em que a organização se torna mais e mais complexa, ressaltam a importância do líder na disseminação de uma orientação de seus liderados em direção a um comportamento mais empreendedor.

FRANCO, M. M. S. Liderança empreendedora e práticas de RH: um estudo sobre a eficácia na promoção do empreendedorismo corporativo. Revista de Empreendedorismo e Gestão de Pequenas Empresas, v. 3, n. 3, p. 104-128, 2014. 
Os estudos sobre liderança, como demonstrado anteriormente nesta produção, têm focado diferenças de estilos e suas influências nas organizações. Um destes estilos surgiu para auxiliar a organização a se tornar capaz de enfrentar novos desafios, a chamada "liderança empreendedora" (MCGRATH; MACMILLAN, 2000; TARABISHY et al., 2005). Este tipo de líder consigue expressar claramente a visão e missão da empresa, sabe coordenar esforços para atingir objetivos comuns e consegue despertar a motivação intrínseca que move as pessoas para se dedicar com afinco às suas responsabilidades. Ele possui todas as condições para estimular estas mesmas pessoas a irem além das práticas impostas para buscar realizações que, de outra forma, não estariam ao alcance da equipe.

O líder bem preparado é o caminho para criar as tais "exceções à regra" impostas pelas práticas institucionalizadas. Dado o julgamento pessoal do líder, este pode determinar quais regras quebrar para obter quais benefícios equivalentes.

Este estilo de liderança influencia a OE da empresa como resultado de seu impacto na postura dos subordinados e também exerce influência sobre as práticas de $\mathrm{RH}$ na OE. Pode-se afirmar também, que práticas de $\mathrm{RH}$ influenciam a liderança empreendedora na OE, uma vez que um time de líderes qualificados faz com que as práticas de $\mathrm{RH}$ sejam menos institucionalizadas, mais genéricas e abrangentes, de forma a permitir que os líderes tenham melhor controle sobre o modelo de gestão de pessoas que melhor explore o potencial empreendedor dos funcionários.

Ambos os dilemas da associação das práticas de RH na OE podem ser resolvidos pela atuação direta do líder, pois este pode adequar melhor as práticas de acordo com cada perfil apresentado pelos indivíduos que compõem a sua equipe, quanto a natureza específica de sua área, departamento ou divisão organizacional.

As dimensões da OE são mais bem direcionadas dentro da organização pelas mãos do líder, pois este, e não o $\mathrm{RH}$, pode decidir como orientar os funcionários para inovar na medida certa, na direção da visão do negócio e para atender a objetivos organizacionais declarados. O líder tem melhores condições do que o RH de distribuir o poder e a autonomia entre aqueles que melhor saberão usar a liberdade para criar e promover mudanças e, consequentemente, como balizar os riscos que cada iniciativa carrega perante o potencial benefício inerente.

FRANCO, M. M. S. Liderança empreendedora e práticas de RH: um estudo sobre a eficácia na promoção do empreendedorismo corporativo. Revista de Empreendedorismo e Gestão de Pequenas Empresas, v. 3, n. 3, p. 104-128, 2014. 
Dadas as inúmeras vantagens da liderança empreendedora na implantação da OE, fica a dúvida: Porque não existe um consenso em torno deste caminho? A resposta fica evidente por meio dos estudos variados apresentados sobre o perfil de liderança: nem todas as pessoas que ocupam posições de liderança nas organizações são de fato líderes.

O fato de um indivíduo ocupar uma função de liderança dentro da organização não necessariamente implica em competências adequadas para a OE. Líderes que não estejam preparados para lidar com funcionários empreendedores, os chamados intraempreendedores, podem perder o controle da situação diante do espírito ousado e aventureiro destes colaboradores.

Líderes empreendedores precisam saber avaliar os riscos que vale a pena correr em instituições que por natureza são avessas ao risco. Precisam saber colher as consequências de atribuir poderes dentro de estruturas em que a hierarquia determina os níveis de poder. Líderes empreendedores precisam incentivar ideias inovadoras em organizações que normalmente refutam o que é diferente e não usual. Precisam valorizar ações e atitudes subjetivas que geram benefícios não mensuráveis enquanto encaram a necessidade de justificar quantitativa e logicamente seus projetos, por meio de projetos e planos detalhados. Não é comum encontrar este perfil de liderança dentro das organizações.

Talvez por isso, as práticas institucionalizadas ganham importância em ambientes que dependem da estruturação cada vez maior para reduzir a dependência de líderes que não estão devidamente capacitados para enfrentar os desafios de gerir pessoas. Uma proposição que merece um estudo específico decorrente desta discussão pode ser: Quanto menor as chances de atrair bons líderes, maior a tendência da estruturação de mais práticas institucionalizadas.

\section{Conclusão}

Em concordância com as pesquisas da área, o presente estudo procurou compreender liderança empreendedora e práticas de recursos humanos em organizações.

FRANCO, M. M. S. Liderança empreendedora e práticas de RH: um estudo sobre a eficácia na promoção do empreendedorismo corporativo. Revista de Empreendedorismo e Gestão de Pequenas Empresas, v. 3, n. 3, p. 104-128, 2014. 
Este estudo procurou trazer como contribuição, um primeiro passo nas discussões a respeito da relevância e da importância da liderança empreendedora e práticas de $\mathrm{RH}$ no grau de $\mathrm{OE}$ nas organizações, composição pouco explorada pela literatura atual, fazendo uma aproximação conceitual dos elementos centrais desses dois temas.

Sendo assim, a proposta deste estudo foi verificar o que mais influencia a OE: liderança empreendedora ou práticas de $\mathrm{RH}$.

Definida a questão, partiu-se para uma revisão bibliográfica objetivando colher informações para a contextualização do tema diante do conhecimento científico produzido até o momento, fundamentando a questão formulada. Com base na revisão bibliográfica, formularam-se quatro proposições que procuraram verificar a relação entre liderança empreendedora e práticas de $\mathrm{RH}$ na OE.

Dados os elementos teóricos apresentados, propôs-se uma discussão ampla em torno do tema, levando à conclusão que a proposição que mais se aproxima de uma possível explicação e resposta à questão proposta é a de número 4: Tanto a liderança empreendedora como as práticas de $\mathrm{RH}$ exercem influência sobre a OE.

Cabe, porém, uma explicação que justifica a escolha desta proposição: a relação entre a liderança e seus funcionários determina o grau de inserção de práticas de $\mathrm{RH}$ no processo de gestão de pessoas para fomentar a OE.

Em organizações com fortes lideranças, as práticas de $\mathrm{RH}$ visam estabelecer direcionamentos amplos e formação de líderes, cuidando mais do desenvolvimento organizacional do que das pessoas, pois estas estão a cargo dos líderes. Em organizações com lideranças fracas, as práticas de $\mathrm{RH}$ visam compensar as deficiências de gestão de pessoas por meio de políticas mais restritivas e controladoras.

Por este motivo, onde há lideranças mal preparadas ou imaturas existe uma grande quantidade de medidas prescritivas que indicam, por exemplo, quais passos o líder deve seguir para fazer uma avaliação de desempenho de seus funcionários, com datas pré-estabelecidas para as reuniões, treinamentos extensivos, formulários pré-preparados, critérios pré-estabelecidos, sistema de pontuação e processos de acompanhamento periódicos e feedbacks.

FRANCO, M. M. S. Liderança empreendedora e práticas de RH: um estudo sobre a eficácia na promoção do empreendedorismo corporativo. Revista de Empreendedorismo e Gestão de Pequenas Empresas, v. 3, n. 3, p. 104-128, 2014. 
Onde há lideranças efetivas, este mesmo processo de avaliação de desempenho não é gerido pelo $\mathrm{RH}$, mas implementado espontaneamente pelas lideranças, sem um processo formal, sem rigidez de regras, porém, sempre humano, imparcial e justo, com benefícios que superam os processos formais de $\mathrm{RH}$. Isto porque, gerir pessoas é diferente de gerir outros tipos de recursos, dada a natureza psicológica que envolve as relações interpessoais entre líder e liderado.

Ao projetar estas mesmas necessidades na caracterização de uma organização orientada ao empreendedorismo, estas diferenças ficam ainda mais evidentes, porque o líder empreendedor, mais do que saber como fazer uma avaliação de desempenho, no exemplo acima, precisa saber que tipo de desempenho tem natureza empreendedora. Como apresentado antes, este desempenho precisa considerar as dimensões da orientação empreendedora: Risco, Inovação, Autonomia, Pró-Atividade e Competitividade Agressiva.

Este mecanismo de compensação, na qual algumas práticas são institucionalizadas para toda a organização, enquanto outras são determinadas pelas lideranças, vai tomando novas formas de equilíbrio em função do grau de maturidade do nível de OE apresentado. Pode-se arriscar na proposição que empresas jovens tendem a ter práticas de $\mathrm{RH}$ mais influentes na $\mathrm{OE}$ do que lideranças e que organizações maduras tendem a ter lideranças mais ativas.

Enquanto as práticas de $\mathrm{RH}$ ajudam a criar uma cultura geral que favoreça o comportamento empreendedor, é por meio de líderes bem preparados que as realizações efetivamente empreendedoras surgem dentro da organização. A atuação dos líderes é local, específica e pontual dentro das áreas sob suas responsabilidades, com pouca abrangência em termos de impacto na cultura organizacional, por isso a necessidade das práticas de $\mathrm{RH}$. Por outro lado, as práticas de $\mathrm{RH}$ são institucionalizadas, atendem a toda a organização e não se aplicam às especificidades de cada função organizacional, cabendo ao líder, explorar a cultura empreendedora para gerar os resultados efetivos esperados pela organização.

Alerta-se que as considerações apresentadas neste ensaio teórico não devem ser consideradas conclusivas, pois os elementos analisados não são 
concretos o suficiente para embasar argumentos a favor da influência de liderança empreendedora ou de práticas de RH na OE.

Da mesma forma que a liderança empreendedora exerce influência sobre as práticas de $\mathrm{RH}$ na $\mathrm{OE}$, pode-se afirmar também que as práticas de $\mathrm{RH}$ influenciam a liderança empreendedora na OE.

Como se observa, este trabalho procurou estabelecer tais relações com base em trabalhos provenientes dos dois campos de estudo, mas não tem a intenção de esgotar o assunto. Entendeu-se que o tema carece ainda de estudos mais profundos no Brasil, aproveitando-se do conhecimento já desenvolvido por outros pesquisadores e publicados em periódicos de língua estrangeira, assim como o campo de empreendedorismo de uma forma geral.

Como sugestão, contudo, faz-se necessário estudar as relações dentro das organizações. Diante da complexidade do fenômeno, estudos futuros, de natureza empírica, poderiam concentrar-se em analisar criteriosamente a influência de liderança empreendedora e práticas de $\mathrm{RH}$ na $\mathrm{OE}$.

Como limitação deste trabalho, destaca-se a ausência de estudos nacionais a respeito das relações conceituais analisadas. Tais relações, bem como sua intensidade e influência, são propostas a partir da reflexão teórica e merecem estudos futuros para sua verificação na prática de organizações brasileiras para que se tornem uma contribuição efetiva ao conhecimento científico sobre orientação empreendedora e seu papel no desenvolvimento organizacional e competitividade baseada em inovação.

\section{Referências}

BRATNICKI, M. Organizational Entrepreneurship: Theoretical Background, Some Empirical Tests, and Directions for Future Research. Human Factors and Ergonomics in Manufacturing, v. 15, n. 1, p. 15-33, 2005.

BROCKBANK, W. If HR Were Really Strategically Proactive: Present and Future Directions in HR's Contribution to Competitive Advantage. Human Resource Management, v. 38, n. 4, p. 337-352, nov. 1999.

COOPER, R. K.; SAWAF, A. Inteligência Emocional na empresa. Rio de Janeiro: Campus, 1997, $381 \mathrm{p}$.

FRANCO, M. M. S. Liderança empreendedora e práticas de RH: um estudo sobre a eficácia na promoção do empreendedorismo corporativo. Revista de Empreendedorismo e Gestão de Pequenas Empresas, v. 3, n. 3, p. 104-128, 2014. 
COVIN, J. G.; COVIN, T. Competitive aggressiveness, environmental context and small firm performance. Entrepreneurship Theory \& Practice, v. 14, n. 4, p. 35-50, 1990.

COVIN, J. G.; SLEVIN, D. P. Strategic management of small firms in hostile and benign environments. Strategic Management Journal, v. 10, n. 1, p. 75-87, 1989.

COVIN, J. G.; SLEVIN, D P. A conceptual model of entrepreneurship as firm behavior. Entrepreneurship Theory and Practice, v. 16, n. 1, p. 7-25, 1991.

DRUCKER, P. F. Inovação e Espírito Empreendedor. São Paulo: Pioneira. 1987, $378 \mathrm{p.}$

DRUCKER, P. F. O Líder do Futuro. São Paulo: Futura, 1996, 316 p.

GRÉGOIRE, D. A.; NOËL, M. X.; DÉRY, R.; BÉCHARD, J-P. Is There Conceptual Convergence in Entrepreneurship Research? A Co-Citation Analysis of Frontiers of Entrepreneurship Research, 1981-2004. Entrepreneurship Theory and Practice, v. 30, n. 3, p. 333-373, 2006.

HASHIMOTO, M. Espírito Empreendedor nas Organizações: aumentando a competitividade através do intra-empreendedorismo. São Paulo: Saraiva, 2006.

HAYTON, J. C. Promoting corporate entrepreneurship through human resource management practices: A review of empirical research. Human Resource Management Review, v. 15, n. 1, p. 21-41, 2005.

HAYTON, J. C. Strategic human capital management in SMEs: An empirical study of entrepreneurial performance. Human Resource Management Journal, v. 42, n. 4, p. 375-391, 2003.

HERSEY, P.; BLANCHARD, K. H. Great ideas revisited: Revisiting the life-cycle theory of leadership. Training \& Development, v. 50, n. 1, p. 42, 1996.

HORNSBY, J. S.; KURATKO, D. F.; MONTAGNO, R. V. Perception of internal factors for corporate entrepreneurship: A comparison of Canadian and U.S. managers. Entrepreneurship Theory and Practice, v. 24, n. 2, p. 9-24, 1999.

IRELAND, R. D.; HITT, M. A. Achieving and maintaining strategic competitiveness in the 21st century: The role of strategic leadership. The Academy of Management Executive, v. 13, n. 1, p. 43-58, 1999.

JONES, F. F.; MORRIS, M. H.; ROCKMORE, W. HR practices that promote entrepreneurship. HRMagazine, Alexandria, United States, Alexandria, v. 40, n. 5, p. 86-86, 1995.

FRANCO, M. M. S. Liderança empreendedora e práticas de RH: um estudo sobre a eficácia na promoção do empreendedorismo corporativo. Revista de Empreendedorismo e Gestão de Pequenas Empresas, v. 3, n. 3, p. 104-128, 2014. 
KAYA, N. The impact of human resource management practices and corporate entrepreneurship on firm performance: evidence from Turkish firms. International Journal of Human Resources Management, v. 17, n. 12, p. 2074-2090, 2006.

KIRKPATRICK, S. A.; LOCKE, E. A. Leadership: Do traits matter? Academy of Management Executive, v. 5, n. 2, p. 48-60, 1991.

KURATKO, D. F.; MONTAGNO, R.V.; HORNSBY, J. S. Developing an Entrepreneurial Assessment Instrument for an Effective Corporate Entrepreneurial Environment. Strategic Management Journal, v. 11, 49-58, 1990.

KURATKO, D.; IRELAND, R.D.; COVIN, J. G.; HORNSBY, J. S. A model of middle level managers'entrepreneurial behaviour. Entrepreneurship Theory and Practice, v. 29 , n. 6 , p. 699-727, nov. 2005.

LADO, A. A.; WILSON, M. Human Resource Systems and Sustained Competitive Advantage: a Competency-based Perspective. Academy of Management Review, v. 19, n. 4, p. 699-727, out. 1994.

LONGENECKER, J.; SCHOEN, J. E. The essence of entrepreneurship. Journal of small business management, v. 13, p. 23-32, 1975.

LUMPKIN, G. T.; DESS, G. G. Clarifying the entrepreneurial orientation construct and linking it to performance. Academy of Management Review, v. 21, n. 1, p. 135-172, 1996.

MCGRATH, R. G.; MACMILLAN, I. C. Assessing technology projects using real options reasoning. Research Technology Management, v. 43, n. 4, p. 35-50, 2000.

MILLER, D. The correlates of entrepreneurship in three types of firms. Management Science, v. 29, n. 7, p. 770-791, 1983.

MILLER, D.; FRIESEN, P. H. Innovation in conservative and entrepreneurial firms: two models of strategic momentum. Strategic Management Journal, v. 3, n. 1, p. 126, 1982.

MORRIS, M. H.; JONES, F. F. Human resource management practices and corporate entrepreneurship: an empirical assessment from the USA. International Journal of Human Resource Management, v. 4, n. 4, p. 873-896, 1993.

PALMINHA, M. A. S. O impacto das práticas de Gestão de Recursos Humanos e da Orientação Empreendedora no desempenho das empresas Portuguesas. 2009, 59 p. Dissertação (Mestrado em Economia e Gestão Internacional) Faculdade de Economia da Universidade do Porto, Portugal, 2009.

ROBBINS, S. P. Comportamento Organizacional. São Paulo: Pearson, Prentice Hall, 2002, 637 p.

FRANCO, M. M. S. Liderança empreendedora e práticas de RH: um estudo sobre a eficácia na promoção do empreendedorismo corporativo. Revista de Empreendedorismo e Gestão de Pequenas Empresas, v. 3, n. 3, p. 104-128, 2014. 
ROUSSEAU, D. M. Psychological contracts in organizations: Understanding written and unwritten agreements. Thousand Oaks, CA: Sage, 1995.

SADLER-SMITH, E.; EL-KOT, G.; LEAT, M. Differentiating work autonomy facets in a non-Western context. Journal of Organizational Behavior, v. 24, n. 6, p. 709-731, 2003.

SCHILDT, H. A.; ZAHRA, S. A.; SILLANPÃ̃̃, A. Scholarly communities in entrepreneurship research: a co-citation analysis. Entrepreneurship Theory and Practice, v. 30, n. 3, p. 399-415, 2006.

SCHULER, R. S. Fostering and Facilitating Entrepreneurship in Organizations: Implications for Organization and Structure and Human Resource Management Practices. Human Resource Management, v. 25, n. 4, p. 607-629, 1986.

SCHUMPETER, J. A. The creative response in economic history. Journal of Economic History, v.7, n. 2, p. 149-159, 1947.

TALES, A. X. Psicologia organizacional: a psicologia na empresa e na vida em sociedade. São Paulo: Ática, 1981.

TARABISHY, A.; SOLOMON, G.; FERNALD, L. W. JR.; SASHKIN, M. The Entrepreneurial Leader's Impact on the Organization's Performance in Dynamic Markets. The Journal of Private Equity, v. 8, n. 4, p. 20-29, 2005.

TIMMONS, J.; SPINELLI, S. New Venture creation - Entrepreneurship for the 21st century. New York: Mc Graw-Hill/Irwin, 2004.

TWOMEY, D.F.; HARRIS D.L. From Strategy to corporate outcomes: Aligning human resource management systems with entrepreneurial intent. International Journal of Competitiveness, v. 10, n. 3, p. 43-55, 2000.

WIKLUND, J. The sustainability of the entrepreneurial orientation-performance relationship. Entrepreneurship Theory and Practice, Oxford, v. 24, n. 1, p. 37-48, 1999.

ZAHRA, S. A.; COVIN, J. G. Contextual influences on the corporate entrepreneurship - performance relationship: a longitudinal analysis. Journal of Business Venturing, Georgia, v. 10, n. 1, p. 43-58, 1995.

Artigo recebido em: 16/03/2014. Artigo aprovado em: 16/10/2014

FRANCO, M. M. S. Liderança empreendedora e práticas de RH: um estudo sobre a eficácia na promoção do empreendedorismo corporativo. Revista de Empreendedorismo e Gestão de Pequenas Empresas, v. 3, n. 3, p. 104-128, 2014. 